\title{
A 6-year experience of CPR outcomes in an emergency department in Thailand
}

This article was published in the following Dove Press journal:

Therapeutics and Clinical Risk Management

7 October 2013

Number of times this article has been viewed

\section{Yuwares Sittichanbuncha' Thidathit Prachanukool' Kittisak Sawanyawisuth ${ }^{2,3}$ \\ 'Emergency Medicine Department, Faculty of Medicine, Ramathibodi Hospital, Mahidol University, Bangkok, Thailand; ${ }^{2}$ Department of Medicine, Faculty of Medicine, Khon Kaen University, Khon Kaen, Thailand; ${ }^{3}$ Research and Diagnostic Center for Emerging Infectious Diseases, Faculty of Medicine, Khon Kaen University, Khon Kaen, Thailand}

Purpose: Sudden cardiac arrest is a common emergency condition found in the emergency department of the hospital. The survival rate of out-of-hospital cardiac arrest patients is $2.0 \%-10.0 \%$ and $7.4 \%-27.0 \%$ percent for in-hospital cardiac arrest patients. The factors for survival outcome are divided into three main groups: patient characteristics, pre-hospital factors, and resuscitated information. The objective of this study was to evaluate the related factors, outcome, and survival rate in patients with cardiac arrest who received cardiopulmonary resuscitation (CPR) at Ramathibodi Emergency Medicine Department. There are limited data for this issue in Thailand and other Asian countries.

Methods: This retrospective study included all patients who were older than 15 years with sudden cardiac arrest and who were resuscitated in the emergency room between January 2005 and December 2010. Descriptive analytic statistics and logistic regressions were used to analyze factors that related to the sustained return of spontaneous circulation (ROSC) and survival at discharge.

Results: There were 181 patients enrolled. The overall sustained ROSC rate was $34.8 \%$ and the survival rate at discharge was $11.1 \%$. There were 145 out-of-hospital cardiac arrest patients, in whom the survival rate was $52.4 \%$ and the survival to discharge rate was $7.6 \%$. For inhospital cardiac arrest, there were 36 patients with a survival rate of $86.1 \%$ and the survival to discharge rate was $25.0 \%$. Statistically significant factors related to sustained ROSC were good and moderate cerebral performance, in-hospital cardiac arrest, beginning of CPR in less than 30 minutes, and cardiopulmonary cause of arrest. The factors influencing survival to discharge were cardiopulmonary causes of cardiac arrest.

Conclusion: Factors associated with sustained ROSC were functional status before cardiac arrest, location of cardiac arrest, duration of CPR, and cause of cardiac arrest. Survival rate was related to the cause of cardiac arrest.

Keywords: CPR, cardiac arrest, predictors, emergency department

\section{Introduction}

Sudden cardiac arrest (SCA) is a fatal condition that needs emergency evaluation and treatment. The survival rate is higher if SCA happens in hospital rather than out of hospital $(7.4 \%-27.0 \%$ versus $2.0 \%-10.0 \%){ }^{1-4}$ Major factors affecting the outcome of SCA include patient characteristics, basic life support, and advanced life support. ${ }^{1-17}$ For example, early cardiopulmonary resuscitation (CPR) within the first minute of the event was associated with a better survival rate. ${ }^{6}$ Even though there are several reports on predictors of CPR outcomes; there are limited data from emergency departments in Thailand and other developing countries. Therapeutic CPR procedures
Correspondence: Kittisak Sawanyawisuth Department of Medicine, Faculty of Medicine, Khon Kaen University, 123 Mitraparp Road, Khon Kaen, 40002, Thailand

Tel +6643363664

Fax +66 43348399

Email kittisak@kku.ac.th 
or factors that were associated with its outcomes at an emergency department in Thailand were studied.

\section{Materials and methods}

The hospital charts of patients aged over 15 years who were diagnosed as SCA, sudden death, unattended death, or received CPR at the Emergency Medicine Department of Ramathibodi hospital were retrospectively reviewed. All patients who met the study criteria between January 2005 and December 2010 were studied.

The emergency department is a section in all hospitals in Thailand. Patients have a right to visit any emergency department in any hospital, regardless of health insurance. All expenses of treatment at the emergency department will be paid for by the Thai government. Ramathibodi Hospital is a university hospital located in the central area of Bangkok, the capital city of Thailand.

Patient characteristics such as age, sex, and previous medical history, Cerebral Performance Categories score (CPC) before cardiac arrest, ${ }^{18}$ location of cardiac arrest, bystander witnessed arrest, bystander CPR performed, first documented pulseless rhythm, time interval from collapse/ arrival to start of CPR in minutes, CPR duration, time of arrest, the leader of the CPR team, initial cause of cardiac arrest, initial capillary or serum glucose, and total ampules of adrenalin used were recorded. The outcomes of the study were outcomes of CPR, discharge status, and factors associated with CPR outcomes and discharge status.

The outcomes of CPR were categorized as no return of spontaneous circulation (ROSC), do not attempt resuscitation (order in the emergency room), ROSC for more than or equal to 20 minutes or sustained ROSC, death in hospital, or survival at discharge.

The study protocol was approved by the institutional review board of human research, Mahidol University. All analyses were done with STATA 11.0 (StataCorp, College Station, TX, USA). Data are presented as means (standard deviation), median (range), or proportion when appropriate. Tests of correlation between outcome variables and study factors were done by descriptive statistics and univariate analysis. Factors with a $P$-value less than 0.05 were included in multivariate logistic regression analysis to calculate adjusted odds ratio and $95 \%$ confidence interval for sustained ROSC more than or equal 20 minutes.

\section{Results}

During the study period, there were 247 patients diagnosed as SCA. Twenty-three and 43 patients were excluded, due to no CPR performed and incomplete data, respectively. In total, 181 patients were studied and included in the analysis. Of those, 107 patients (59.1\%) had ROSC of more than 20 minutes; 87 patients $(81.3 \%)$ died in hospital and 20 patients $(18.7 \%)$ were alive. Of those patients who died, 44 patients $(50.6 \%)$ died at the emergency department. Most patients (nine patients or $45.0 \%$ ) who survived had a CPR score of category 1 as shown in Figure 1.

Characteristics of patients with and without sustained ROSC of more than 20 minutes were compared (Table 1). There were ten factors that were significantly associated with sustained ROSC of more than 20 minutes which were encephalopathy, the CPC score card before cardiac arrest, location of SCA, witnessed SCA, having bystander CPR performed, time to start of CPR, duration of CPR, cause of SCA, initial capillary glucose, and adrenalin use (Table 1). After adjustment by multivariate logistic regression analysis, there were only four factors significantly associated with sustained ROSC of more than 20 minutes as shown in Table 2 which were CPC score before SCA, location of SCA, CPR duration, and initial cause of SCA. In terms of factors associated with being alive or dead, the initial cause of SCA was the only significant factor. Survivors had a higher proportion

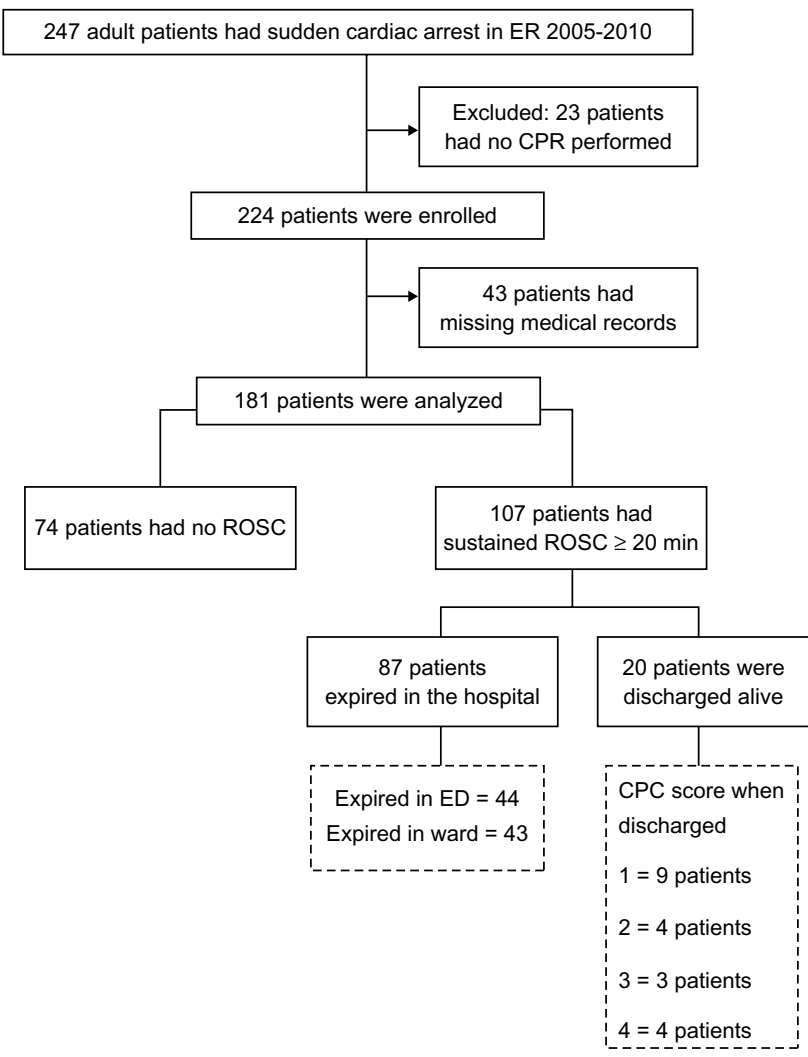

Figure I Flow diagram of the study.

Abbreviations: CPC, Cerebral Performance Categories; CPR, cardiopulmonary resuscitation; ED, emergency department; ER, emergency room; ROSC, return of spontaneous circulation. 
Table I Clinical characteristics of all sudden cardiac arrest patients by sustained ROSC of more than 20 minutes

\begin{tabular}{|c|c|c|c|}
\hline \multirow[t]{2}{*}{ Characteristics } & \multicolumn{2}{|c|}{$\begin{array}{l}\text { Sustained ROSC } \geq \\
20 \text { minutes }\end{array}$} & \multirow[t]{2}{*}{$P$-value } \\
\hline & $\begin{array}{l}74 \text { failure, } \\
\text { n (\%) }\end{array}$ & $\begin{array}{l}\text { I } 07 \text { success, } \\
\text { n (\%) }\end{array}$ & \\
\hline \multicolumn{4}{|l|}{ Sex } \\
\hline Male & $38(5 \mathrm{I} .4)$ & $53(49.5)$ & 0.810 \\
\hline Female & $36(48.7)$ & $54(50.8)$ & \\
\hline Age (years), mean $\pm 2 S D$ & $66.2 \pm 17.1$ & $64.0 \pm 17.1$ & 0.401 \\
\hline \multicolumn{4}{|l|}{ Medical history* } \\
\hline Hypertension & $39(52.7)$ & $59(55.1)$ & 0.746 \\
\hline Diabetes mellitus & $23(31.1)$ & $38(35.5)$ & 0.535 \\
\hline Encephalopathy & $32(43.2)$ & $26(24.3)$ & 0.007 \\
\hline Intrinsic heart disease & $20(27.0)$ & $4 \mid(38.3)$ & 0.114 \\
\hline Pulmonary disease & $20(27.0)$ & $33(30.8)$ & 0.579 \\
\hline Liver disease & $6(8.1)$ & II (I0.3) & 0.622 \\
\hline Renal disease & $19(25.7)$ & $35(32.7)$ & 0.309 \\
\hline Malignancy & $15(20.3)$ & $23(21.5)$ & 0.842 \\
\hline Metastatic malignancy & $7(9.5)$ & $16(15.0)$ & 0.275 \\
\hline Unknown/not collected & $12(16.2)$ & $14(13.1)$ & 0.555 \\
\hline $\begin{array}{l}\text { CPC score before } \\
\text { cardiac arrest }\end{array}$ & & & $<0.001$ \\
\hline 1 and 2 & $56(75.7)$ & $102(95.3)$ & \\
\hline 3 and 4 & I8 (24.3) & $5(4.7)$ & \\
\hline Location of cardiac arrest & & & $<0.001$ \\
\hline In-hospital & $5(6.8)$ & $31(29.0)$ & \\
\hline Out-of-hospital & $69(93.2)$ & $76(71.0)$ & \\
\hline Witness arrest* & $48(64.9)$ & $91(85.1)$ & 0.002 \\
\hline Bystander performed CPR* & $15(20.3)$ & $36(33.7)$ & 0.049 \\
\hline $\begin{array}{l}\text { First documented } \\
\text { pulseless rhythm }\end{array}$ & & & 0.140 \\
\hline Nonshockable & $65(87.8)$ & $85(79.4)$ & \\
\hline Shockable & $9(12.2)$ & $22(20.6)$ & \\
\hline $\begin{array}{l}\text { Collapse to start CPR } \\
\text { (minutes) median } \\
\text { (minimum, maximum) }\end{array}$ & $30(0,300)$ & $10(0,95)$ & $<0.001$ \\
\hline Collapse to start CPR & & & $<0.001$ \\
\hline$<10$ minutes & $7(9.5)$ & $37(34.6)$ & \\
\hline$\geq 10$ minutes & $67(90.5)$ & $70(65.4)$ & \\
\hline $\begin{array}{l}\text { CPR duration (minutes) } \\
\text { median (minimum, } \\
\text { maximum) }\end{array}$ & $30(3,125)$ & $16(2,120)$ & $<0.001$ \\
\hline CPR duration & & & $<0.001$ \\
\hline$<30$ minutes & I8 (24.3) & $82(76.6)$ & \\
\hline$\geq 30$ minutes & $56(75.7)$ & $25(23.4)$ & \\
\hline Doctor shift & & & 0.403 \\
\hline Night & I8 (24.3) & $29(27.1)$ & \\
\hline Day & $27(36.5)$ & $29(27.1)$ & \\
\hline Afternoon & $29(39.2)$ & $49(45.8)$ & \\
\hline Team leader & & & 0.113 \\
\hline Staff & $18(24.3)$ & $16(15.0)$ & \\
\hline Resident & $56(75.7)$ & $91(85.0)$ & \\
\hline Initial cause of arrest & & & $<0.001$ \\
\hline Cardiopulmonary cause ${ }^{\dagger}$ & II (I4.9) & $58(54.2)$ & \\
\hline Non-cardiopulmonary $\ddagger$ & $63(85.14)$ & 49 (45.79) & \\
\hline
\end{tabular}

(Continued)
Table I (Continued)

\begin{tabular}{|c|c|c|c|}
\hline \multirow[t]{2}{*}{ Characteristics } & \multicolumn{2}{|c|}{$\begin{array}{l}\text { Sustained ROSC } \geq \\
20 \text { minutes }\end{array}$} & \multirow[t]{2}{*}{$P$-value } \\
\hline & $\begin{array}{l}74 \text { failure, } \\
\text { n (\%) }\end{array}$ & $\begin{array}{l}107 \text { success, } \\
\text { n (\%) }\end{array}$ & \\
\hline $\begin{array}{l}\text { Initial serum glucose } \\
\text { (mg \%) median } \\
\text { (minimum, maximum) }\end{array}$ & II $7.5(15,500)$ & $152(|I, 5| 4)$ & 0.048 \\
\hline $\begin{array}{l}\text { Adrenaline (ampules) median } \\
\text { (minimum, maximum) }\end{array}$ & $6(I, 2 I)$ & $3(0,15)$ & $<0.001$ \\
\hline Adrenaline use (ampules) & & & $<0.001$ \\
\hline$<5$ ampules & $17(34.8)$ & $68(63.55)$ & \\
\hline$\geq 5$ ampules & $57(77.03)$ & $39(36.45)$ & \\
\hline
\end{tabular}

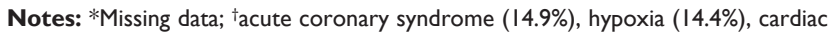
arrhythmia $(7.2 \%)$, massive pulmonary embolism $(1.7 \%)$; ${ }^{\ddagger}$ metabolic cause $(6.1 \%)$, sepsis $(5.5 \%)$, hemorrhage, non-trauma (3.3\%), neurologic emergency $(2.2 \%)$, drug toxicity $(2.2 \%)$, traumatic blunt injury $(1.1 \%)$, anaphylaxis $(0.6 \%)$, traumatic penetrating injury $(0.6 \%)$, unknown/not collected $(40.3 \%)$.

Abbreviations: CPC, Cerebral Performance Categories; CPR, cardiopulmonary resuscitation; ROSC, return of spontaneous circulation; SD, standard deviation.

of having a cardiopulmonary cause of SCA than non-survivors ( $80.0 \%$ versus $48.3 \% ; P=0.010)$ as shown in Table 3 .

\section{Discussion}

The initial cause of SCA was the main factor associated with sustained ROSC of more than 20 minutes and being a survivor of SCA at the emergency department. These causes include acute coronary syndrome, cardiac arrhythmia, massive pulmonary embolism, and hypoxemia. All mentioned disease syndromes have a potential to be corrected if treated promptly. The outcomes of CPR therefore are better than other causes.

The duration of collapse before CPR of less than 10 minutes was another predictor for having sustained ROSC of more than 20 minutes. This finding is comparable to previous studies. ${ }^{5,9,10,12}$ The rate of successful CPR in SCA patients caused by shockable rhythms with defibrillation decreases by $7.0 \%-10.0 \%$ for each minute of delay. ${ }^{16} \mathrm{~A}$ previous study showed that CPR within 15 minutes had better survival outcomes. ${ }^{13}$ This study emphasizes that early CPR within 10 minutes also gave a better outcome of sustained ROSC of more than 20 minutes.

Table 2 Multivariate logistic regression results on factors associated with sustained ROSC of more than 20 minutes

\begin{tabular}{ll}
\hline Factors & Adjusted odds ratio $(95 \% \mathrm{Cl})$ \\
\hline CPC score $\leq 2$ before arrest & $10.80(2.52-46.28)$ \\
Location of arrest: in-hospital & $8.55(2.41-30.30)$ \\
CPR duration $<30$ minutes & $18.93(7.26-49.38)$ \\
Cause of arrest: cardiopulmonary & $10.59(3.89-28.83)$ \\
\hline
\end{tabular}

Abbreviations: $\mathrm{Cl}$, confidence interval; CPC, Cerebral Performance Categories; CPR, cardiopulmonary resuscitation; ROSC, return of spontaneous circulation. 
Table 3 Clinical factors of sudden cardiac arrest patients who died or survived

\begin{tabular}{|c|c|c|c|}
\hline \multirow[t]{2}{*}{ Factors } & \multicolumn{2}{|c|}{ Hospital course } & \multirow[t]{2}{*}{$P$-value } \\
\hline & $\begin{array}{l}87 \text { hospital } \\
\text { death, } \\
\text { n (\%) }\end{array}$ & $\begin{array}{l}20 \text { survival } \\
\text { to discharge, } \\
\text { n (\%) }\end{array}$ & \\
\hline Encephalopathy & $87(100)$ & $20(100)$ & 0.621 \\
\hline \multicolumn{4}{|l|}{ arrest } \\
\hline 1 and 2 & $82(94.3)$ & $20(100)$ & \\
\hline 3 and 4 & $5(5.8)$ & $0(0)$ & \\
\hline Location of arrest & & & 0.080 \\
\hline In-hospital & $22(25.3)$ & $9(45.0)$ & \\
\hline Out-of-hospital & $65(74.7)$ & II (55.0) & \\
\hline Witness arrest & $87(100)$ & $20(100)$ & 0.493 \\
\hline Bystander performed CPR & $87(100)$ & $20(100)$ & 0.887 \\
\hline First documented & & & 0.356 \\
\hline \multicolumn{4}{|l|}{ pulseless rhythm } \\
\hline Nonshockable & 71 (8I.6) & $14(70.0)$ & \\
\hline Shockable & $16(18.4)$ & $6(30.0)$ & \\
\hline Collapse to start CPR & & & 0.108 \\
\hline$<10$ minutes & $27(31.0)$ & $10(50.0)$ & \\
\hline$\geq 10$ minutes & $60(69.0)$ & $10(50.0)$ & \\
\hline CPR duration & & & 0.395 \\
\hline$<30$ minutes & $65(74.7)$ & $17(85.0)$ & \\
\hline$\geq 30$ minutes & $22(25.3)$ & $3(15.0)$ & \\
\hline Initial cause of arrest & & & $0.010 *$ \\
\hline Cardiopulmonary cause & $42(48.3)$ & $16(80.0)$ & \\
\hline Non-cardiopulmonary & 45 (5।.7) & $4(20.0)$ & \\
\hline Adrenaline use (ampules) & & & 0.238 \\
\hline$<5$ ampules & $53(60.9)$ & $15(75.0)$ & \\
\hline$\geq 5$ ampules & $34(39.1)$ & $5(25.0)$ & \\
\hline
\end{tabular}

Notes: $*$ Standard error $=2.57$, OR $(95 \% \mathrm{Cl})=4.29(1.33-13.86)$.

Abbreviations: $\mathrm{Cl}$, confidence interval; $\mathrm{CPC}$, Cerebral Performance Categories; CPR, cardiopulmonary resuscitation; OR, odds ratio.

In our sample, $76.8 \%$ of SCAs were witnessed, but only $28.2 \%$ of these witnesses performed CPR. The low rate CPR being performed by bystanders may indicate little knowledge of CPR by the general public. This pre-hospital resuscitation is an important factor for successful CPR as shown by this and previous studies. ${ }^{1,2,7-11} \mathrm{CPR}$ training for the public should be emphasized in the Thai population.

Similar to a previous study ${ }^{16}$ the location of SCA, CPR duration, and initial cause of SCA were associated with sustained ROSC of more than 20 minutes. CPC score before SCA was another predictor for sustained ROSC of more than 20 minutes. CPC scores of 1 and 2 had 10.8 times the chance of having successful CPR (Table 2). In addition, a cardiopulmonary cause had a higher chance of successful CPR and survival rate (Tables 2 and 3). Noncardiac causes accounted for 34.1\% (276/809) of patients who had out-of-hospital cardiac arrest with a survival rate of $11.3 \% .{ }^{19}$ The low survival rate in noncardiac causes was mainly due to an initial asystole rhythm. Ventricular fibrillation or a shockable arrhythmia of cardiopulmonary causes may have better CPR outcomes. In addition, there are community-based interventions such as defibrillators to improve survival rate in those with SCA of cardiac origin. ${ }^{19}$

The limitations of this study are the retrospective study design and small numbers of subjects. Missing or incomplete data was the main limitation; $17.0 \%$ of patients were excluded due to incomplete data. In this study, causes of cardiac arrest were defined as cardiopulmonary or non-cardiopulmonary causes. Unlike previous reports or guidelines, ${ }^{19-23}$ causes were not well defined. A cardiac cause may be the possible cause of cardiac arrest if there was no obvious identified cause. In this study, $40.0 \%$ of patients had unidentified causes of cardiac arrest. Another limitation is the heterogeneous character of the population in the study. The outcomes, however, were statistically significant with respect to the studied variables. The results of this study show that society or public health programs such as training of basic life support or availability of defibrillators in communities are needed to improve CPR outcomes.

\section{Conclusion}

The CPC score before SCA, location of SCA, CPR duration, and initial cause of SCA were associated with sustained ROSC for more than 20 minutes for SCA patients treated at the emergency department. Survivors had a higher proportion of having a cardiopulmonary cause of SCA than non-survivors.

\section{Acknowledgment}

The authors thank Professor James A Will (University of Wisconsin) for his kind review of the manuscript.

\section{Disclosure}

The authors report no conflicts of interest in this work.

\section{References}

1. McNally B, Robb R, Mehta M, et al; Centers for Disease Control and Prevention. Out-of-hospital cardiac arrest surveillance - Cardiac Arrest Registry to Enhance Survival (CARES), United States, October 1, 2005-December 31, 2010. MMWR Surveill Summ. 2011;60(8):1-19.

2. Fairbanks RJ, Shah MN, Lerner EB, Ilangovan K, Pennington EC, Schneider SM. Epidemiology and outcomes of out-of-hospital cardiac arrest in Rochester, New York. Resuscitation. 2007;72(3):415-424.

3. Krittayaphong R, Saengsung P, Chawaruechai T, Yindeengam A, Udompunturak S. Factors predicting outcome of cardiopulmonary resuscitation in a developing country: the Siriraj cardiopulmonary resuscitation registry. J Med Assoc Thai. 2009;92(5):618-623. 
4. Peberdy MA, Kaye W, Ornato JP, et al. Cardiopulmonary resuscitation of adults in the hospital: a report of 14720 cardiac arrests from the National Registry of Cardiopulmonary Resuscitation. Resuscitation. 2003;58(3):297-308.

5. Hayakawa K, Tasaki O, Hamasaki T, et al. Prognostic indicators and outcome prediction model for patients with return of spontaneous circulation from cardiopulmonary arrest: the Utstein Osaka Project. Resuscitation. 2011;82(7):874-880.

6. Langhelle A, Tyvold SS, Lexow K, Hapnes SA, Sunde K, Steen PA. In-hospital factors associated with improved outcome after out-ofhospital cardiac arrest. A comparison between four regions in Norway. Resuscitation. 2003;56(3):247-263.

7. Baker PW, Conway J, Cotton C, et al; Clinical Investigators. Defibrillation or cardiopulmonary resuscitation first for patients with out-of-hospital cardiac arrests found by paramedics to be in ventricular fibrillation? A randomised control trial. Resuscitation. 2008;79(3):424-431.

8. Cooper S, Janghorbani M, Cooper G. A decade of in-hospital resuscitation: outcomes and prediction of survival? Resuscitation. 2006;68(2):231-237.

9. Ong ME, Ng FS, Anushia P, et al. Comparison of chest compression only and standard cardiopulmonary resuscitation for out-of-hospital cardiac arrest in Singapore. Resuscitation. 2008;78(2):119-126.

10. Søreide E, Morrison L, Hillman K, et al. The formula for survival in resuscitation. Resuscitation. 2013.

11. Field JM, Hazinski MF, Sayre MR, et al. Part 1: executive summary: 2010 American Heart Association Guidelines for Cardiopulmonary Resuscitation and Emergency Cardiovascular Care. Circulation. 2010;122(18 Suppl 3):S640-S656.

12. Hollenberg J, Herlitz J, Lindqvist J, et al. Improved survival after out-of-hospital cardiac arrest is associated with an increase in proportion of emergency crew - witnessed cases and bystander cardiopulmonary resuscitation. Circulation. 2008;118(4):389-396.

13. Amnuaypattanapon K, Udomsubpayakul U. Evaluation of related factors and the outcome in cardiac arrest resuscitation at Thammasat Emergency Department. J Med Assoc Thai. 2010;93 Supp1 7:S26-S34.

14. Martinell L, Larsson M, Bång A, et al. Survival in out-of-hospital cardiac arrest before and after use of advanced postresuscitation care: a survey focusing on incidence, patient characteristics, survival, and estimated cerebral function after postresuscitation care. Am J Emerg Med. 2010;28(5):543-551.
15. Saghafinia M, Motamedi MH, Piryaie M, et al. Survival after inhospital cardiopulmonary resuscitation in a major referral center. Saudi J Anaesth. 2010;4(2):68-71.

16. Neumar RW, Otto CW, Link MS, et al. Part 8: adult advanced cardiovascular life support: 2010 American Heart Association Guidelines for Cardiopulmonary Resuscitation and Emergency Cardiovascular Care. Circulation. 2010;122(18 Suppl 3):S729-S767.

17. Kayser RG, Ornato JP, Peberdy MA; American Heart Association National Registry of Cardiopulmonary Resuscitation. Cardiac arrest in the Emergency Department: a report from the National Registry of Cardiopulmonary Resuscitation. Resuscitation. 2008;78(2):151-160.

18. Cummins RO, Chamberlain DA, Abramson NS, et al. Recommended guidelines for uniform reporting of data from out-of-hospital cardiac arrest: the Utstein Style. A statement for health professionals from a task force of the American Heart Association, the European Resuscitation Council, the Heart and Stroke Foundation of Canada, and the Australian Resuscitation Council. Circulation. 1991;84(2):960-975.

19. Moriwaki Y, Tahara Y, Kosuge T, Suzuki N. Etiology of out-of-hospital cardiac arrest diagnosed via detailed examinations including perimortem computed tomography. J Emerg Trauma Shock. 2013;6(2):87-94.

20. Lindner TW, Langorgen J, Sunde K, et al. Factors predicting the use of therapeutic hypothermia and survival in unconscious out-of-hospital cardiac arrest patients admitted to the ICU. Crit Care. 2013;17(4):R147.

21. Jacobs I, Nadkarni V, Bahr J, et al; International Liason Committee on Resusitation. Cardiac arrest and cardiopulmonary resuscitation outcome reports: update and simplification of the Utstein templates for resuscitation registries. A statement for healthcare professionals from a task force of the international liaison committee on resuscitation (American Heart Association, European Resuscitation Council, Australian Resuscitation Council, New Zealand Resuscitation Council, Heart and Stroke Foundation of Canada, InterAmerican Heart Foundation, Resuscitation Council of Southern Africa). Resuscitation. 2004;63(3):233-249.

22. Pell JP, Sirel JM, Marsden AK, Ford I, Walker NL, Cobbe SM. Presentation, management, and outcome of out of hospital cardiopulmonary arrest: comparison by underlying aetiology. Heart. 2003;89(8): 839-842.

23. Engdahl J, Bång A, Karlson BW, Lindqvist J, Herlitz J. Characteristics and outcome among patients suffering from out of hospital cardiac arrest of non-cardiac aetiology. Resuscitation. 2003;57(1):33-41.
Therapeutics and Clinical Risk Management

\section{Publish your work in this journal}

Therapeutics and Clinical Risk Management is an international, peerreviewed journal of clinical therapeutics and risk management, focusing on concise rapid reporting of clinical studies in all therapeutic areas, outcomes, safety, and programs for the effective, safe, and sustained use of medicines. This journal is indexed on PubMed Central, CAS,

\section{Dovepress}

EMBase, Scopus and the Elsevier Bibliographic databases. The manuscript management system is completely online and includes a very quick and fair peer-review system, which is all easy to use. Visit http://www.dovepress.com/testimonials.php to read real quotes from published authors. 